\title{
Determination of Surface Tension and Surface Segregation of Sn-Mg Liquid Alloy
}

\author{
Adiba Rais $^{1}$, Ahmed Jouaiti ${ }^{2}$, Rachid Lbibb ${ }^{3}$ \\ 1,2,3 Laboratoire de Développement Durable. Université Sultan Moulay Slimane, Faculté des Sciences et Techniques, B.P 523, Béni Mellal, \\ Maroc
}

\begin{abstract}
The regular associated model has been applied to investigate the surface tension and surface segregation of Sn-Mg liquid using Butler's equation. Application of model to Sn-Mg systems allows us to explain his thermodynamic behaviour by the existence of $\mathrm{SnMg}_{2}$ associates. Computed surface tension is in disagreement with those of literature and decreases when temperature increases. Calculated surface tension curve versus composition shows a maximum. This irregularity is explained by the presence of clusters in liquid. Calculation of surface composition suggests segregation of tin atoms to the surface from $x_{S n}=0.33$.
\end{abstract}

Keywords: Sn-Mg alloys, regular associated model, Surface properties, thermodynamic properties

\section{Introduction}

One of the important surface properties of liquid alloys is surface tension. It plays an important role to understand surface-related phenomena, such as interfacial adhesion and wettability between the soldering material and the substrate. Indeed, in order to produce a good wettability and strong adhesion at the substrate/solder interface, the surface tension of liquid solder must be low.

Due to the experimental difficulties, it is impossible to measure the surface tension of all materials which are being developed. For this purpose, several authors have proposed calculation methods of surface tension of liquid [1-11]. In our previous work [11], we have presented calculation method using Butler's equation [12] for the systems having a thermodynamic behaviour characterised by short-range order explained by the presence of associated atomic groups (cluster) in liquid. This method relates surface tension of liquid alloys to the thermodynamic data of the bulk phase. It is useful for systems that we can't measure this property or there are discrepancies between the experimental measurements. It also allows us to explain the irregularities observed in surface tension isotherms and to predict its variation with temperature.

In this work we have made an attempt to investigate the surface tension and surface segregation of Sn-Mg liquids. Our concern in these liquid alloys stems from the fact that it could be used in soldering processes in the field of advanced microelectronics and semiconductor packaging. Sn-Mg alloys are used as materials for lead-free solders [13] and have been found useful in flip-chip technology [14]. The only data of surface tension of Sn-Mg liquid alloys that exist in literature are those of Eremenko et al. at $1073 \mathrm{~K}$ [15]. They show that the measurements at a given composition are not reproducible. The presence of highly reactive trace impurities, such as oxygen, in the surrounding atmosphere affects the measure of surface tension of tin based alloys; that explains the discrepancies in literature data. In order to review those literature data, we calculated the surface tension of Sn-Mg liquids alloys versus composition and temperature from thermodynamics properties of bulk phase using Butler's equation.
Many authors have determined the enthalpy of formation of Sn-Mg liquid [16-19]. Their results show disagreement. The enthalpy of formation selected for this work is that of Steiner et al. [16] which is in accordance with that of Hultgren et al. [20]. The only data for free enthalpy of formation available in literature are that of [20]. The thermodynamic behaviour of studied system is characterised by very strong negative departure to ideality, suggesting strong short-range order explained by the presence of associated atomic groups (cluster) in liquid. The regular associated model developed elsewhere [21-27] can be applied to explain the thermodynamics behaviours of these systems.

The aim of this work is the application of regular associated model to Sn-Mg liquids alloys to compute surface tension and surface segregation versus temperature and composition using Butler's equation.

\section{Butler's equation in Regular Associated Model}

The Butler's equation has been established [12] assuming an equilibrium between a bulk phase and a surface which is regarded as hypothetical phase. Its expression for liquid binary alloys is as follows:

$$
\begin{aligned}
\sigma & =\sigma_{A}+\frac{R T}{\alpha_{A}} \ln \frac{x_{A}^{s}}{x_{A}^{b}}+\frac{1}{\alpha_{A}}\left(\bar{G}_{A}^{E, s}\left(T, x_{A}^{s}\right)-\bar{G}_{A}^{E, b}\left(T, x_{A}^{b}\right)\right) \\
& =\sigma_{B}+\frac{R T}{\alpha_{B}} \ln \frac{x_{B}^{s}}{x_{B}^{b}}+\frac{1}{\alpha_{B}}\left(\bar{G}_{B}^{E, s}\left(T, x_{A}^{s}\right)-\bar{G}_{B}^{E, b}\left(T, x_{A}^{b}\right)\right)
\end{aligned}
$$

where $R$ is the gas constant, $T$ the temperature, $\sigma_{i}$ the surface tension of pure liquid $i$ and $\alpha_{i}$ the molar surface area in monolayer of pure liquid $i$ ( $i=\mathrm{A}$ or $\mathrm{B}$ ). $\alpha_{i}$ is obtained as $\alpha_{i}=L N_{o}^{1 / 3} V_{i}^{2 / 3}$, where $N_{\mathrm{o}}$ is the Avogadro's number, $V_{i}$ the molar volume of pure liquid $i$ and $L$ the correction factor resulting from the surface structure. The value of $L$ is usually set to be 1.091 for liquid metals assuming closed packed structure [28].

$\bar{G}_{i}^{E, s}\left(T, x_{A}^{s}\right)$ and $\bar{G}_{i}^{E, b}\left(T, x_{A}^{b}\right)$ are the partials excess free enthalpies of component $i$ versus temperature $T$ and composition $x_{A}^{s}$ and $x_{A}^{b}$ in surface and bulk phases 


\section{International Journal of Science and Research (IJSR) \\ ISSN (Online): 2319-7064}

Index Copernicus Value (2013): 6.14 | Impact Factor (2015): 6.391

respectively. Their expressions are deduced from free enthalpy expressed in regular associated model [11].

In associated model the mixture $\mathrm{A}-\mathrm{B}$ consists of three species, the "free" atoms $A$ and $B$ and the cluster $A_{m} B_{n} \equiv C$ ( $m$ and $n$ are small integers). The expression of the molar free enthalpy is given by:

$$
\begin{aligned}
& G_{b}^{f}\left(x_{A}^{b}, T\right)=N_{C}^{b} z^{b} \Delta H^{\circ}+N_{T}^{b} z^{b}\left(\omega_{A B} X_{A}^{b} X_{B}^{b}\right. \\
& \left.+\omega_{A C} X_{A}^{b} X_{C}^{b}+\omega_{B C} X_{B}^{b} X_{C}^{b}\right)-T N_{C}^{b} \Delta S^{\circ}-T S_{b}^{\text {conf }}
\end{aligned}
$$

where $z^{\mathrm{b}}$ is the coordination number of bulk phase, and $N_{C}^{b}, X_{i}^{b}$ and $N_{T}^{b}$ are respectively the number of cluster, the molar fraction of species $i$ and the total number of species in bulk ternary system. $\Delta H^{\circ}, \Delta S^{\circ}$ and $S_{b}^{\text {conf }}$ are respectively the enthalpy and the entropy of formation of cluster, $S_{b}^{\text {conf }}$ is the molar configurational entropy and $\omega_{i j}$ are the binary interaction parameters.

The superscript and subscript b refer to the quantities at the bulk phases.

Free enthalpy in the surface phase has the same expression as equation (2) by replacing superscript and subscript b by s. We assume that $\Delta H^{\circ}, \Delta S^{\circ}$ and interaction parameters $\omega_{i j}$ are constant in the surface and bulk phases. The expression of Butler's equation in associated model is obtained by substituting the expressions of partials excess free enthalpies of components expressed in regular associated model in equation (1).

\section{Calculation of Surface Tension}

Using the enthalpy of formation and excess free enthalpy of studied liquid alloys in the whole range of composition, we can apply the regular associated model in order to elucidate the nature and the stability of clusters and to determine the binary interaction parameters $\omega_{i j}$ for each system. Usually, the compound with the highest melting temperature persists in liquid phase, and the short-range order can be explained by the presence of cluster that has the same stoichiometry. Once given the parameters $\Delta H^{\circ}, \Delta S^{\circ}$ and $\omega_{i j}$, we calculate, versus composition, the partials free enthalpies of components in surface and bulk phases at the chosen temperature. Then, the two equations on the right-hand side of Eq. (1) become an equation with unknown $x_{A}^{s}$. This equation is solved for $x_{A}^{s}$ and the value of $x_{A}^{s}$ is substituted in Eq. (1) to calculate surface tension $\sigma$ of liquid alloy. The coordination number in the surface is taken as that for closed packed structures $\left(\mathrm{z}^{\mathrm{s}} / \mathrm{z}^{\mathrm{b}}=9 / 12\right)$. The prediction of surface tension of liquid requires knowledge of those of the pure metals. Surface tension data of pure $\mathrm{Sn}$ and $\mathrm{Mg}$, versus temperature, are taken from Ref [29].

The Sn-Mg system exhibits only one congruently compound $\mathrm{SnMg}_{2}$. The thermodynamics functions show a minimum at the composition corresponding to $\mathrm{SnMg}_{2}$. Hence, the thermodynamic behaviour can be explained by the presence of $\mathrm{SnMg}_{2}$ clusters in liquid. The calculation was carried out with three interaction parameters:
$\omega_{S n, M g}=-3.18 \mathrm{~kJ} / \mathrm{mol}, \omega_{S n, S n M g_{2}}=-4.34 \mathrm{~kJ} / \mathrm{mol}$, $\omega_{\mathrm{Mg}, \mathrm{SnMg}_{2}}=-3.87 \mathrm{~kJ} / \mathrm{mol}$.

The enthalpy and the entropy of formation of cluster are respectively: $\Delta H^{\circ}=-2.25 \mathrm{~kJ} / \mathrm{mol}, \Delta S^{\circ}=7.62 \mathrm{~J} / \mathrm{K} \mathrm{mol}$.

The calculated values of enthalpy of formation and excess free enthalpy and those of literature are presented in figure 1. They show a good agreement. In figure 2, we presented a number of different species in pseudo-ternary system, the melt is not strongly associated $\left(\mathrm{X}_{\mathrm{SnMg} 2}=0.3\right)$.

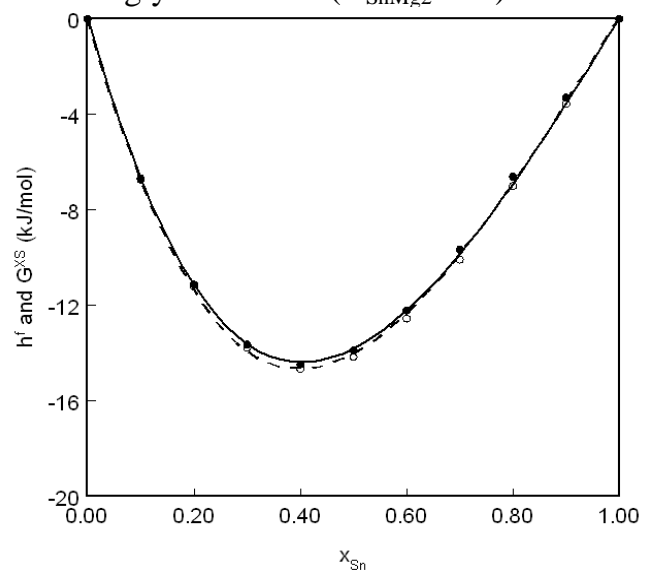

Figure 1: Enthalpy and excess free enthalpy of formation of Sn-Mg liquid at $\mathrm{T}=1073 \mathrm{~K}$.

$\mathrm{h}^{\mathrm{f}}:(\bullet)$ literature [16]; (-) calculated

$\mathrm{G}^{\mathrm{XS}}:$ (o) literature [21]; (---) calculated

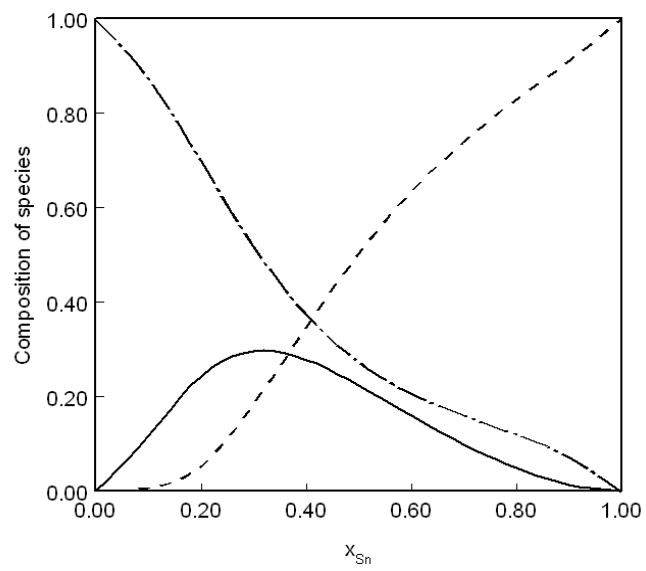

Figure 2: Composition of species of Sn-Mg liquid at $\mathrm{T}=1073 \mathrm{~K}$.

(--) free Sn, (-- ) free Mg, (-) Cluster $\mathrm{SnMg}_{2}$

Computed surface tension of Sn-Mg liquid alloys at $1073 \mathrm{~K}$ is presented versus composition of tin in figure 3 and consigned in table 1. Quantitatively, it is not in good agreement with that of Eremenko et al. [15]. The disagreement between computed surface tension and experimental data is due to the presence of highly reactive trace impurities, such as oxygen, in the surrounding atmosphere which affects the measure. But the calculated surface tension curve presents an irregularity, as that of literature, near composition corresponding to the stoichiometry of cluster $\mathrm{SnMg}_{2}\left(\mathrm{x}_{\mathrm{Sn}}=0.333\right)$. The surface tension curve of Eremenko et al. [15] shows an abrupt decrease at $\mathrm{x}_{\mathrm{Sn}}=0.333$ and our calculated surface tension presents a maximum at this composition. According to 


\section{International Journal of Science and Research (IJSR) \\ ISSN (Online): 2319-7064 \\ Index Copernicus Value (2013): 6.14 | Impact Factor (2015): 6.391}

Trifinov and Aleksandrov [30,31], the presence of maxima in the curve of surface tension means that the clusters are not surface active relative to pure component. The calculation of surface tension at two other temperatures (873 K and 1273 $\mathrm{K})$ shows that surface tension decreases with increasing temperature (figure 4).

Table 1: Calculated surface tension and surface composition of Sn-Mg liquid

\begin{tabular}{|c|c|c|}
\hline & \multicolumn{2}{|c|}{$S n-M g(1073 K)$} \\
\hline$x_{S n}^{b}$ & $\sigma_{\text {calc }}(\mathrm{N} / \mathrm{m})$ & $x_{S n}^{s}$ \\
\hline 0 & 0.548 & 0 \\
\hline 0.1 & 0.568 & 0.051 \\
\hline 0.2 & 0.589 & 0.172 \\
\hline 0.3 & 0.598 & 0.192 \\
\hline 0.4 & 0.598 & 0.414 \\
\hline 0.5 & 0.590 & 0.546 \\
\hline 0.6 & 0.575 & 0.685 \\
\hline 0.7 & 0.558 & 0.812 \\
\hline 0.8 & 0.541 & 0.903 \\
\hline 0.9 & 0.527 & 0.961 \\
\hline 1 & 0.515 & 1 \\
\hline
\end{tabular}

The calculation of surface composition (figure 5 and table 1) shows that there is little segregation of $\mathrm{Mg}$ until $\mathrm{x}_{\mathrm{Sn}}=0.333$, at which the tin becomes to segregate in surface. The segregation of $\mathrm{Mg}$ for $\mathrm{x}_{\mathrm{Sn}}<0.333$ is explained by the fact that there are many free atoms of $\mathrm{Mg}$ in pseudo-ternary system and almost atoms of tin are engaged in clusters (figure 2). At $\mathrm{x}_{\mathrm{Sn}}=0.333$, the number of clusters becomes to decrease and we have more free atoms of tin that can segregate in surface. The calculation of surface segregation versus temperature shows that as the temperature increases there is little change in the segregation of $\mathrm{Mg}$ and the decrease of that of tin (figure 5).

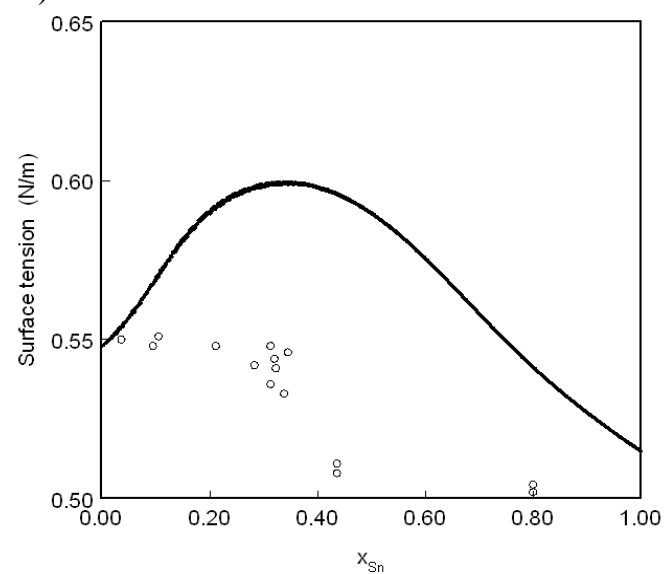

Figure 3: Surface tension of Sn-Mg liquid at $\mathrm{T}=1073 \mathrm{~K}$ (-) calculated, (o) Eremenko [15]

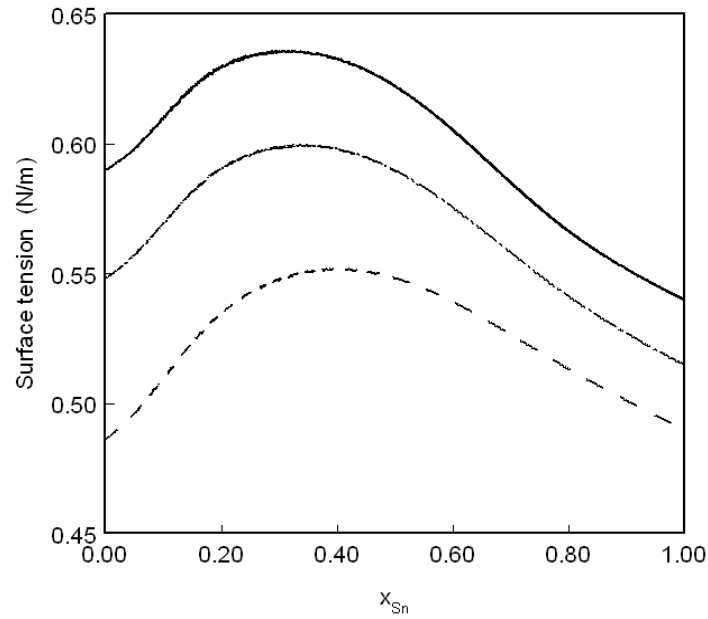

Figure 4: Surface tension of Sn-Mg liquid at different temperatures.

(-) $873 \mathrm{~K}$; (--) $1073 \mathrm{~K}$; (-----) $1273 \mathrm{~K}$

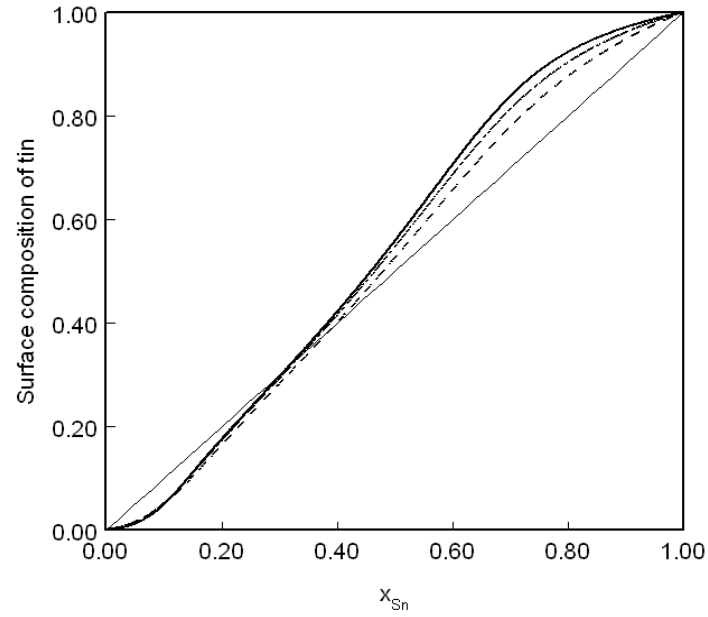

Figure 5: Surface composition of Sn at different temperatures.

(-) $873 \mathrm{~K}$; (---) $1073 \mathrm{~K}$; (-----) $1273 \mathrm{~K}$

\section{Conclusion}

Thermodynamics behaviors of $\mathrm{Sn}-\mathrm{Mg}$ liquid have been explained by the presence of $\mathrm{SnMg}_{2}$ clusters. Near the composition corresponding to cluster stoichiometry, calculated surface tension of Sn-Mg liquid shows a maximum explained by the presence of clusters in liquid. The surface tension decreases when temperature increases due to dissociation of clusters by thermal agitation. Calculation of surface composition shows segregation of tin from $x_{\mathrm{Sn}}=0.33$. The segregation of tin atoms decreases when temperature increases.

\section{References}

[1] L.C. Prassad, R.N. Singh, Phys. Rev, 24, pp.13768, 1991.

[2] L.C. Prassad, A. Mikula, J. Alloys Comp, 282, pp. 279, 1999.

[3] N. Jha, A.K. Mishra, J. Alloys Comp, 329, pp. 224, 2001.

[4] O. Akinlade, R.N. Singh, J. Alloys Comp, 33, pp.84, 2002. 


\section{International Journal of Science and Research (IJSR) \\ ISSN (Online): 2319-7064}

Index Copernicus Value (2013): 6.14 | Impact Factor (2015): 6.391

[5] L.C. Prassad, A. Mikula, J. Alloys Comp, 314, pp. 193, 2001.

[6] T. Tanaka, K. Hack, T. Lida, S. Hara, Z. Metallkd, 87, pp.380,1996).

[7] T.P. Hoar, D.A. Melford, Trans. Faraday Soc, 53, pp. 315, 1957.

[8] K.S. Yeum, R. Speiser, D.R. Poirier, Metall. Trans, B 20, pp.693, 1989.

[9] H.K. Lee, J.P. Hajra, M.G. Frohberg, Z. Metallkd, 83, pp. 8, 1992.

[10] M. Roesner-Kuhn, G. Kuppermann, U. Thiedemann, K. Drewes, T. Schmidt-Lehmann, M.G. Frohberg, Ber. Bunsenges. Phys. Chem, 102, pp. 1163, 1989.

[11] A. Rais, R. Lbibb, J. Alloys and compounds, 381, pp. 197, 2004.

[12] J.A.V. Butler, Proc. R. Soc. Lond. Ser. A, 135, pp. 348, 1932.

[13] J.H. Lau, Van Nostrand Reinhold, New York, 1991.

[14] H.K. Jong, W.J. Sang, M.L. Hyuck, J. Electron. Mater, 31(6), pp. 557, 2002.

[15] V.N. Eremenko, Yu.N. Ivashenko, G.P. Khilya, Iz. AN. SSSR. Metall, 3, pp. 38, 1977.

[16] A. Steiner,E. Miller, K.L. Komarek, Trans. Met. Soc. Aime, 230, pp. 1361, 1964.

[17]F. Sommer, J.J. Lee, B. Predel, Metallkd, 71, pp. 818, 1980.

[18] V.N. Eremenko, G.M. Lukasheenko, Ukr. Khim. Zh, 29, pp. 896, 1963.

[19] J.M. Eldridge, E. Miller, K.L. Komarek, Trans. Metall. Soc. Aime, 239, pp. 775, 1967.

[20] R. Hultgren, P.D. Desai, D.T. Hawkins, M. Gleiser, K.K. Kelly, selected values of thermodynamics properties of Binary alloys, ASM International, Metals Park, OH,1973.

[21] A.B. Bhatia, W.H. Hargrove, Phys. Rev. B 8-10, pp. 3186, 1974.

[22]F. Sommer, Z. Metallkd. 73, pp. 72, 1982.

[23] F. Sommer, Z. Metallkd. 73, pp.77, 1982.

[24]C. Bergman, R. Castanet, H. Saïd, M. Gilbert, J.C. Mathieu, J.Less-Common Met. 85, pp. 121, 1982.

[25] R. Castanet, M. Gilbert, J.C. Mathieu, J. Less-Common Met. 96, pp. 1, 1984.

[26] H. Saïd, R. Castanet, M. Gilbert, J.C. Mathieu, J. LessCommon Met. 96, pp.79, 1984.

[27] R. Lbibb, M. Gilbert, R. Castanet, J. Alloys Comp. 205, pp. 253, 1994.

[28] T. Tanaka, T. Iida, Steel Res. 65, pp. 21, 1994.

[29]B.J. Keene, NPL Report DMM(A)39 dated November 1991.

[30] N.A. Trifinov, G.K. Aleksandrov, Iz. Sektora. Fiz. Khim. Anal. 12, pp. 85, 1940.

[31] N.A. Trifinov, Iz. Sektora. Fiz. Khim. Anal. 12, pp.103, 1940. 